\title{
ESTABILIDADE DE CULTIVARES DE MILHO EM TRÊS ECOSSISTEMAS DO NORDESTE BRASILEIRO'
}

\author{
HÉLIO WILSON LEMOS DE CARVALHO ${ }^{2}$, MARIA DE LOURDES DA SILVA LEAL², MANOEL XAVIER DOS SANTOS ${ }^{3}$, \\ ANTÔNIO AUGUSTO TEIXEIRA MONTEIRO ${ }^{4}$, MILTON JOSÉ CARDOSO ${ }^{5}$ e BENEDITO CARLOS LEMOS DE CARVALHO
}

\begin{abstract}
RESUMO - No decorrer dos anos agrícolas de 1995, 1996 e 1997, doze genótipos de milho (Zea mays, L.) foram avaliados em 75 ambientes do Nordeste brasileiro, distribuídas nos ecossistemas dos Tabuleiros Costeiros, Agreste e Sertão, em blocos ao acaso, com três repetições, visando conhecer a estabilidade de produção desses materiais. As produtividades médias alcançadas foram altas, atestando o potencial do Nordeste brasileiro para a produção do milho. Os Tabuleiros Costeiros se apresentam como uma nova região para exploração competitiva do milho. Os híbridos mostraram melhor adaptação que as cultivares, sobressaindo o BR 3123, com melhor rendimento, apesar de ser mais exigente, nas condições desfavoráveis, nos três ecossistemas. Os híbridos, à exceção do BR 2121, mostraram boa estabilidade de produção nos ambientes considerados $\left(\mathrm{R}^{2}>80 \%\right)$. Entre as cultivares de melhor adaptação, apenas a BR 106 mostrou baixa estabilidade nesses ambientes $\left(\mathrm{R}^{2}=75 \%\right)$. Para o Nordeste brasileiro, a cultivar BR 5033 se aproximou do genótipo ideal proposto pelo modelo.
\end{abstract}

Termos para indexação: Zea mays, interação genótipo x ambiente, variedades, híbridos.

\section{STABILITY OF CORN CULTIVARS IN THREE ECOSYSTEMS OF BRAZILIAN NORTHEAST}

\begin{abstract}
The production stability of twelve corn genotypes was evaluated in 75 different environments of the Coastal Tablelands, "Agreste" and "Sertão" ecosystems, during the 1995, 1996 and 1997 growing seasons in randomized block design with three replications, aiming at the recommendation of adapted materials. High mean productivities were slightly similar at ecosystem level. Coastal Tablelands should be highlighted as a new competitive area of corn production. Hybrids showed better environment adaptation than cultivars, BR 3123 showing the best yielding in all the three ecosystems in spite of being the most exigent under unfavourable conditions. Except for BR 2121, all hybrids had good production stability in all of the environments considered $\left(\mathrm{R}^{2}>80 \%\right)$. Among the cultivars with better adaptation, only BR 106 showed low stability in these environments $\left(\mathrm{R}^{2}=75 \%\right)$. For the Brazilian Northeast, BR 5033 cultivar was the ideal genotype proposed by this model.
\end{abstract}

Index terms: Zea mays, genotype environment interaction, varieties, hybrids.

\section{INTRODUÇÃO}

As condições edafoclimáticas do Nordeste brasileiro permitem, com algumas restrições, o desenvolvimento do milho em toda a sua extensão. Nos últimos

\footnotetext{
${ }^{1}$ Aceito para publicação em 16 de novembro de 1999.

${ }^{2}$ Eng. Agrôn., M.Sc., Embrapa-Centro de Pesquisa Agropecuária dos Tabuleiros Costeiros (CPATC), Av. BeiraMar, 3250, Caixa Postal 44, CEP 49001-970 Aracaju, SE. E-mail: helio@cpatc.embrapa.br

${ }^{3}$ Eng. Agrôn., Ph.D., Embrapa-Centro Nacional de Pesquisa de Milho e Sorgo (CNPMS), Caixa Postal 152, CEP 35701-970 Sete Lagoas, MG. E-mail: xavier@cnpma.embrapa.br

${ }^{4}$ Eng. Agrôn., M.Sc., Empresa de Pesquisa Agropecuária do Ceará
}

anos, registrou-se um aumento gradativo no rendimento desse cereal, como conseqüência do uso de cultivares melhoradas, de híbridos de milho, e do desenvolvimento de sistemas de produção mais eficientes. Existem áreas que têm mostrado grande

(EPACE), Caixa Postal 60, CEP 60115-221 Fortaleza CE

${ }^{5}$ Eng. Agrôn., Ph.D., Embrapa-Centro de Pesquisa Agropecuária do Meio-Norte (CPAMN), Caixa Postal 01, CEP 64006-220 Teresina, PI.

E-mail: milton@cpamn.embrapa.br

${ }^{6}$ Eng. Agrôn., Ph.D., Embrapa/Empresa Baiana de Desenvolvimento Agrícola (EBDA), CEP 4635-150 Salvador, BA. E-mail: ebdaexp@ebda.ba.gov.br 
aptidão para o incremento da cultura, a exemplo dos Cerrados da Bahia, Zona do Cariri no Ceará e áreas de pousio de cana-de-açúcar, nos Tabuleiros Costeiros, onde o rendimento de grãos tem alcançado o patamar de 5,5 t/ha (Carvalho et al., 1998b).

Em 1994, a Região Nordeste produziu 2.721.911 toneladas de milho, em uma área de 3.206.200 ha, com um rendimento médio de $849 \mathrm{~kg} / \mathrm{ha}$ (Anuário Estatístico do Brasil, 1995). Essa área produtora encontrase distribuída nos ecossistemas dos Tabuleiros Costeiros, Agreste e Sertão, onde o milho é submetido a diferentes condições ambientais, tornando necessário o desenvolvimento de um programa intensivo de avaliação de cultivares e híbridos de milho visando fornecer alternativas aos produtores, no tocante à escolha de materiais mais responsivos quando submetidos aos diferentes sistemas de produção prevalecentes nesses ecossistemas. A recomendação de cultivares nesta ampla região não deve ser facultada apenas com base no comportamento médio observado nos diferentes ambientes, uma vez que algumas delas apresentam melhores rendimentos em ambientes específicos, tornando ineficiente o processo de recomendação.

A presença da interação cultivares $x$ ambiente assume importância fundamental no processo de recomendação, e é necessário minimizar o seu efeito, o que é possível através da seleção de cultivares com maior estabilidade fenotípica (Ramalho et al., 1993). A ocorrência dessa interação tem sido observada em diversos trabalhos com o milho na região (Costa, 1976; Carvalho et al., 1992, Cardoso et al., 1997; Carvalho et al., 1998a, 1998b), onde ficou demonstrada a necessidade de selecionar cultivares adaptadas e de maior estabilidade para difusão aos produtores.

A estabilidade, segundo Torres (1988), é uma característica com controle genético, e apresenta uma herdabilidade menor que a produtividade. Além disso, segundo o mesmo autor, não ocorre correlação significativa entre esses caracteres, o que mostra que eles devem ter controle genético independente. Apesar de a produtividade ser um caráter de baixa herdabilidade, a seleção com vistas a essa característica é mais efetiva do que a estabilidade (Ramalho et al., 1993); portanto, em um programa de melhoramento deve-se, primeiro, selecionar com vistas à produtividade, e, dentro dos materiais selecionados, fazer a seleção quanto à estabilidade (Torres, 1988).
A estabilidade em milho está relacionada com a base genética da cultivar. Resultados de alguns trabalhos têm revelado que cultivares menos homogêneas apresentam produção mais estável que as mais homogêneas (Ruschel, 1968; Lemos, 1976), o que evidencia que essa maior estabilidade é consequiência do grande número de genótipos que formam essas cultivares (Paterniani, 1965). Por outro lado, resultados contraditórios foram obtidos por Ruschel \& Penteado (1970), Costa (1976) e Naspolini Filho (1976), os quais mostraram maior estabilidade em materiais mais homogêneos, por terem, na heterozigose apresentada na maioria dos locos, maior capacidade de processar as trocas ambientais de forma mais eficiente que a mistura de genótipos, sobressaindo os híbridos simples, com maior eficiência em desenvolver essa capacidade (Allard \& Bradshaw, 1964). A ocorrência desses resultados contraditórios sugere a importância do estudo da interação cultivares $\mathrm{x}$ ambientes, visando fornecer mais subsídios e maior compreensão do comportamento de diferentes cultivares de milho quando submetidas a diferentes condições ambientais (Arias, 1996).

Os Tabuleiros Costeiros do Nordeste, com suas áreas planas ou levemente onduladas, que favorecem cem práticas de agricultura mecanizada, com temperaturas amenas e um período chuvoso constante, têm mostrado grande potencial para o desenvolvimento do milho, destacando-se os Tabuleiros de Sergipe, Alagoas, Bahia e Piauí. As produtividades médias registradas têm oscilado entre 5 e 7 t/ha (Carvalho et al., 1992, 1998a, 1998b; Cardoso et al., 1997). Apesar de essa região apresentar a cana-deaçúcar como principal cultura, além de grandes áreas exploradas com fruteiras, especialmente da laranja, o milho surge como uma alternativa de certa importância econômica, dada a sua adaptação neste ecossistema, a facilidade de mecanização da cultura e a proximidade dos centros consumidores.

No ecossistema do Agreste, o milho exerce grande importância econômica, por ser, juntamente com o feijão, a base de sustentação familiar da maioria dos agricultores. Nesse ecossistema, em razão da regularidade climática, a ocorrência de frustração de safras é menos frequiente. No ecossistema do Sertão, concentra-se a maior área plantada com milho no Nordeste brasileiro, e é nela que o milho tem gran- 
de importância social e econômica, apesar da ocorrência de frustrações de safras, em razão do regime pluviométrico inconstante. Nessa região concentramse os grandes pólos de desenvolvimento da cultura, onde a produtividade tem ultrapassado o limite de 6,0 t/ha, em razão do uso de tecnologias modernas de produção, inclusive, irrigação, como tem sido verificado nas regiões de Barreiras, na Bahia, e em Balsas, no Maranhão.

Este trabalho teve como objetivo avaliar a estabilidade de produção de genótipos de milho nos três ecossistemas que compõem o Nordeste brasileiro.

\section{MATERIAL E MÉTODOS}

O Nordeste brasileiro encontra-se convencionalmente dividido em três zonas: Tabuleiros Costeiros, Agreste, e Sertão. Estas duas últimas, segundo Silva et al. (1993), formam essencialmente a Região Semi-Árida, abrangendo $70 \%$ da área do Nordeste e $13 \%$ do Brasil.

Segundo Silva et al. (1993), que apresentam maior detalhamento dos diferentes ecossistemas que formam a Região Nordeste, predomina, na zona do Sertão, em função da baixa pluviosidade, uma vegetação tipo caatinga hipoxerófila, nas áreas menos secas, e de caatinga hiperxerófila, nas áreas de seca mais acentuada. Segundo esses autores, os solos nas zonas do Sertão e do Agreste variam de arenosos, profundos e de baixa fertilidade natural a solos rasos e pedregosos de alta fertilidade natural, encontrando-se, também, solos medianamente profundos e de alta fertilidade natural. No Sertão, o clima é quente, semi-árido, com período chuvoso de outubro a abril. No Agreste, região de clima mais ameno, o período chuvoso é de janeiro a junho. De modo geral, segundo Silva et al. (1993), a precipitação média anual, nessas zonas, é de $500 \mathrm{~mm}$ a $800 \mathrm{~mm}$. Os Tabuleiros Costeiros acompanham todo o litoral do Nordeste, e apresentam superfícies planas a ligeiramente onduladas. As diferentes texturas entre os principais tipos de solos variam desde argila arenosa a areia e são, de maneira geral, de fertilidade natural muito baixa. A vegetação natural foi, provavelmente, constituída por florestas tropicais (Mata Atlântica). A precipitação média anual varia de $500 \mathrm{~mm}$ a $1.500 \mathrm{~mm}$. As temperaturas médias anuais oscilam em torno de $26^{\circ} \mathrm{C}$.

Nos anos agrícolas de 1995, 1996 e 1997 foram realizados 75 ensaios, a saber: 20 nos Tabuleiros Costeiros, 18 no Agreste e 37 no Sertão, em diferentes classes de solos (Latossolo Vermelho-Amarelo distrófico, Podzólico Vermelho-Amarelo, Areia Quartzosa, Aluviais, Brunizém-
Escuro, Brunizém-Avermelhado, Regossolo), entre as lati-

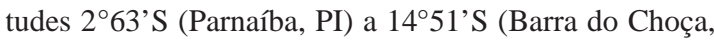
BA).

Utilizou-se o delineamento experimental em blocos ao acaso, com doze tratamentos, em três repetições. Cada parcela constou de quatro fileiras de 5,0 $\mathrm{m}$ de comprimento, com espaçamento de $1,0 \mathrm{~m}$, com $0,50 \mathrm{~m}$ entre covas dentro das fileiras. Foram colocadas três sementes/cova deixando-se duas plantas/cova, após o desbaste. Foram colhidas as duas fileiras centrais de forma integral, correspondendo a uma área útil de $10,0 \mathrm{~m}^{2}$. As adubações foram realizadas de acordo com as recomendações dos resultados das análises de solo; utilizaram-se como fontes de $\mathrm{N}, \mathrm{P}$ e K a uréia, o superfosfato simples e o cloreto de potássio, respectivamente, com exceção dos ensaios realizados nos municípios de Riacho do Cavalo e Itaporanga, no ano de 1997, no Sertão da Paraíba, que não receberam qualquer adubação.

Após a análise de variância no local, efetuaram-se as análises de variâncias conjuntas dentro de cada ecossistema e global. Os parâmetros de adaptabilidade e estabilidade foram estimados utilizando-se a metodologia proposta por Cruz et al. (1989), a qual baseia-se na análise de regressão bissegmentada, tendo como parâmetros de adaptabilidade, a média, e a resposta linear aos ambientes desfavoráveis $\left(\beta_{1 i}\right)$ e aos favoráveis $\left(\beta_{1}+\beta_{2}\right)$. A estabilidade dos materiais é avaliada pelos desvios da regressão $\sigma \mathrm{ji}$ de cada cultivar, de acordo com as variações ambientais. Utilizou-se o seguinte modelo:

$\mathrm{Y}_{\mathrm{ij}}=\beta_{0 \mathrm{i}}+\beta_{\mathrm{li}} \mathrm{I}_{\mathrm{j}}+\beta_{2 \mathrm{i}} \mathrm{T}\left(\mathrm{I}_{\mathrm{j}}\right)+\sigma_{\mathrm{ij}}+\bar{\epsilon}_{\mathrm{ij}}$ onde $\mathrm{Y}_{\mathrm{ij}}:$ média da cultivar i no ambiente; $\mathrm{I}_{\mathrm{j}}$ : índice ambiental; $\mathrm{T}\left(\mathrm{I}_{\mathrm{j}}\right)=0$ se $\mathrm{I}_{\mathrm{j}}<0$; $\mathrm{T}\left(\mathrm{I}_{\mathrm{j}}\right)=\mathrm{I}_{\mathrm{j}}-\overline{\mathrm{I}}_{+}$se $\mathrm{I}_{\mathrm{j}}>0$, sendo $\mathrm{I}_{+}$a média dos índices $\mathrm{I}_{\mathrm{j}}$ positivos; $\beta_{0 \mathrm{i}}$ : média geral da cultivar i; $\beta_{\mathrm{li}}$ : coeficiente de regressão linear associado à variável $\mathrm{I}_{\mathrm{j}} ; \beta_{2 \mathrm{i}}$ : coeficiente de regressão linear associado à variável $\mathrm{T}\left(\mathrm{I}_{\mathrm{j}}\right) ; \sigma_{\mathrm{ij}}$ : desvio da regressão linear; $\bar{\epsilon}_{\mathrm{ij}}$ : erro médio experimental.

\section{RESULTADOS E DISCUSSÃO}

As análises de variância por ambiente mostraram efeitos significativos entre as cultivares em 73 dos 75 ensaios, evidenciando, assim, variações entre as cultivares nos vários ambientes. Os coeficientes de variação oscilaram de 5,3\% a 20,6\%, conferindo boa previsão aos ensaios (Scapim et al., 1995). Na análise de variância conjunta dentro de cada ecossistema, e na global, os coeficientes de variação oscilaram de $10,6 \%$ a $12,7 \%$. As produtividades de grãos foram de $4.360 \mathrm{~kg} / \mathrm{ha}, 4.538 \mathrm{~kg} / \mathrm{ha}, 4.213 \mathrm{~kg} / \mathrm{ha}$ e $4.330 \mathrm{~kg} / \mathrm{ha}$ (Tabelas 1 e 2) o que evidencia o potencial da cultura 
TABELA 1. Estimativas dos parâmetros de adaptabilidade e estabilidade de 12 genótipos de milho nos ecossistemas dos Tabuleiros Costeiros do Agreste e do Sertão do Nordeste brasileiro, nos anos de 1995/96/97.

\begin{tabular}{|c|c|c|c|c|c|c|c|c|}
\hline \multirow[t]{2}{*}{ Genótipo } & \multicolumn{3}{|c|}{ Médias (kg/ha) } & \multirow[t]{2}{*}{$\beta_{1}$} & \multirow[t]{2}{*}{$\beta_{2}$} & \multirow[t]{2}{*}{$\beta_{1}+\beta_{2}$} & \multirow{2}{*}{$\begin{array}{l}\text { Q.M. dos desvios } \\
\text { da regressão }\left(\sigma_{\mathrm{di}}^{2}\right)\end{array}$} & \multirow[t]{2}{*}{$\mathrm{R}^{2}$} \\
\hline & Geral & Desfavorável & Favorável & & & & & \\
\hline & & & & \multicolumn{2}{|c|}{ Tabuleiros Costeiros } & & & \\
\hline BR $3123^{1}$ & 5.448 & 4.298 & 6.854 & $1,47^{* *}$ & $-0,04^{\text {ns }}$ & $1,43^{* *}$ & $984.072,50^{++}$ & 89 \\
\hline Germinal $600^{2}$ & 5.180 & 4.156 & 6.431 & $1,32^{* *}$ & $-0,39^{*}$ & $0,93^{\text {ns }}$ & $1.702 .938,37^{++}$ & 78 \\
\hline Agromen $2010^{2}$ & 5.160 & 4.303 & 6.206 & $1,04^{\text {ns }}$ & $0,00^{\text {ns }}$ & $1,05^{\mathrm{ns}}$ & $1.188 .365,62^{++}$ & 78 \\
\hline BR $2121^{2}$ & 4.697 & 4.102 & 5.424 & $0,78^{* *}$ & $0,02^{\text {ns }}$ & $0,81^{\text {ns }}$ & $1.032 .742,56^{++}$ & 70 \\
\hline BR 5011 ${ }^{3}$ & 4.276 & 3.333 & 5.429 & $1,18^{*}$ & $-0,22^{\text {ns }}$ & $0,96^{\text {ns }}$ & $867.841,43^{++}$ & 85 \\
\hline BR $5004^{3}$ & 4.262 & 3.582 & 5.092 & $0,96^{\text {ns }}$ & $-0,46^{* *}$ & $0,50^{* *}$ & $919.501,18^{++}$ & 76 \\
\hline BR $5028^{3}$ & 4.174 & 3.512 & 4.981 & $0,94^{\text {ns }}$ & $0,15^{\text {ns }}$ & $1,09^{\text {ns }}$ & $624.921,43^{\text {ns }}$ & 85 \\
\hline BR $5033^{3}$ & 4.026 & 3.199 & 5.036 & $1,07^{\text {ns }}$ & $0,11^{\text {ns }}$ & $1,18^{\text {ns }}$ & $435.688,94^{\text {ns }}$ & 91 \\
\hline BR $473^{3}$ & 3.891 & 3.222 & 4.709 & $0,79^{* *}$ & $0,17^{\text {ns }}$ & $0,98^{\text {ns }}$ & $588.865,43^{\text {ns }}$ & 82 \\
\hline BR $106^{3}$ & 3.874 & 3.140 & 4.772 & $0,84^{* *}$ & $-0,00^{\text {ns }}$ & $0,83^{\text {ns }}$ & $1.737 .174,37^{++}$ & 61 \\
\hline BR $5037^{3}$ & 3.798 & 3.166 & 4.570 & $0,81_{*{ }_{* k}}^{*}$ & $0,27^{\mathrm{ns}}$ & $1,09^{\text {ns }}$ & $531.265,87^{\mathrm{ns}}$ & 85 \\
\hline CMS $52^{4}$ & 3.539 & 2.939 & 4.272 & $0,75^{* *}$ & $0,37^{* *}$ & $1,12^{\mathrm{ns}}$ & $840.936,94^{++}$ & 76 \\
\hline & & & & \multicolumn{2}{|c|}{ Agreste } & & & \\
\hline BR $3123^{1}$ & 5.482 & 4.072 & 6.610 & $1,12^{*}$ & $0,32^{* *}$ & $1,45^{* *}$ & $1.154 .958,87^{+}$ & 89 \\
\hline Germinal $600^{2}$ & 5.038 & 3.919 & 5.394 & $0,93^{\text {ns }}$ & $0,12^{\mathrm{ns}}$ & $1,06^{\mathrm{ns}}$ & $\begin{array}{l}1.17 .993,62^{+} \\
\end{array}$ & 84 \\
\hline Agromen $2010^{2}$ & 5.029 & 3.562 & 6.203 & $1,16^{* *}$ & $0,07^{\text {ns }}$ & $1,23^{*}$ & $491.777,06^{\text {ns }}$ & 95 \\
\hline BR $2121^{2}$ & 4.885 & 3.101 & 6.311 & $1,42^{* *}$ & $-0,09^{\text {ns }}$ & $1,33^{* *}$ & $910.118,37^{+}$ & 93 \\
\hline BR 5011 3 & 4.398 & 3.344 & 5.241 & $0,80^{* *}$ & $-0,04^{\text {ns }}$ & $0,75^{*}$ & $511.662,94^{\text {ns }}$ & 89 \\
\hline BR 5004 & 4.365 & 3.116 & 5.365 & $1,03^{\text {ns }}$ & $-0,17^{\text {ns }}$ & $0,86^{\text {ns }}$ & $1.169 .884,25$ & 85 \\
\hline BR $5028^{3}$ & 4.353 & 3.065 & 5.383 & $1,09^{\text {ns }}$ & $-0,09^{\text {ns }}$ & $1,00^{\text {ns }}$ & $845.820,81^{+}$ & 90 \\
\hline BR $5033^{3}$ & 4.313 & 2.901 & 5.442 & $1,10^{\text {ns }}$ & $\begin{array}{l}-0,0,7^{\text {ns }} \\
-0,\end{array}$ & $1,02^{\text {ns }}$ & $\begin{array}{l}547.844,81^{\text {ns }} \\
547.020\end{array}$ & 93 \\
\hline BR $473^{3}$ & 4.258 & 3.403 & 4.941 & $0,77^{* *}$ & $0,27^{*}$ & $1,05^{\text {ns }}$ & $628.025,62^{\mathrm{ns}}$ & 90 \\
\hline BR $106^{3}$ & 4.226 & 3.059 & 5.152 & $0,95^{\text {ns }}$ & $-0,26^{*}$ & $0,69^{* * *}$ & $804.769,06^{+}$ & 87 \\
\hline BR $5037^{3}$ & 4.167 & 3.122 & 5.002 & $0,89^{\text {ns }}$ & $-0,15^{\text {ns }}$ & $0,74^{* *}$ & $715.342,37^{+}$ & 87 \\
\hline CMS 52 $2^{4}$ & 3.939 & 3.159 & 4.563 & $0,69^{* *}$ & $-0,08^{\text {ns }}$ & $0,77^{*}$ & $802.889,06^{+} 89$ & 80 \\
\hline & & & & & & & & \\
\hline BR $3123^{1}$ & 5.370 & 4.325 & 6.600 & $1,27^{* *}$ & $-0,2^{\text {ns }}$ & $1,06^{\mathrm{ns}}$ & $1.428 .653,12^{++}$ & 81 \\
\hline Germinal $600^{2}$ & 5.080 & 3.986 & 6.368 & $1,27^{* *}$ & $-0,41^{* *}$ & $0,85^{\mathrm{ns}}$ & $814.373,18^{++}$ & 88 \\
\hline Agromen $2010^{2}$ & 4.543 & 3.468 & 5.808 & $1,21^{* *}$ & $-0,36^{* * *}$ & $0,85^{\text {ns }}$ & $1.012 .943,06^{++}$ & 84 \\
\hline BR $2121^{2}$ & 4.437 & 3.702 & 5.302 & $0,89^{* *}$ & $-0,23^{*}$ & $0,65^{* *}$ & $1.276 .444,75^{++}$ & 70 \\
\hline BR 5011 & 4.213 & 3.420 & 5.147 & $1,00^{\text {ns }}$ & $0,57^{* *}$ & $1,58^{* * *}$ & $1.052 .944,00^{++}$ & 83 \\
\hline BR $5004^{3}$ & 4.021 & 3.059 & 5.152 & $1,06^{\text {ns }}$ & $0,05^{\text {ns }}$ & $1,11^{\text {ns }}$ & $813.241,43^{++}$ & 85 \\
\hline BR $5028^{3}$ & 3.926 & 3.135 & 4.856 & $0,92^{\text {ns }}$ & $0,08_{* *}^{\text {ns }}$ & $1,00^{\text {ns }}$ & $828.064,50^{++}$ & 81 \\
\hline BR $5033^{3}$ & 3.911 & 3.202 & 4.747 & $0,78^{* * *}$ & $0,61^{* *}$ & $1,40^{* * *}$ & $842.732,25^{++}$ & 81 \\
\hline BR $473^{3}$ & 3.880 & 2.918 & 5.013 & $1,04^{\text {ns }}$ & $\begin{aligned} & 0,017^{* * *} \\
-0 & \end{aligned}$ & $0,67^{* *}$ & $1.141 .550,12^{++}$ & $\begin{array}{l}01 \\
78\end{array}$ \\
\hline BR $106^{3}$ & 3.823 & 3.107 & 4.665 & $0,88^{*}$ & $0,12^{\text {ns }}$ & $0,99^{\text {ns }}$ & $659.156,68^{++}$ & 83 \\
\hline BR $5037^{3}$ & 3.751 & 3.028 & 4.601 & $0,85^{* *}$ & $0,19^{\text {ns }}$ & $1,04^{\text {ns }}$ & $727.988,68^{++}$ & 81 \\
\hline CMS $52^{4}$ & 3.602 & 2.945 & 4.374 & $0,80^{* *}$ & $-0,03^{\text {ns }}$ & $0,76^{*}$ & $747.085,18^{++}$ & 77 \\
\hline
\end{tabular}

*e ** Significativo a $5 \%$ e $1 \%$ de probabilidade, pelo teste t de Student, respectivamente, para $\beta_{1}, \beta_{2}$ e $\beta_{1}+\beta_{2}$

${ }^{++}$Significativo a $1 \%$ de probabilidade, pelo teste F, para $\sigma_{\text {di }}^{2}$.

${ }^{1}$ Híbrido triplo.

3 Horido dup

${ }^{4}$ População. 


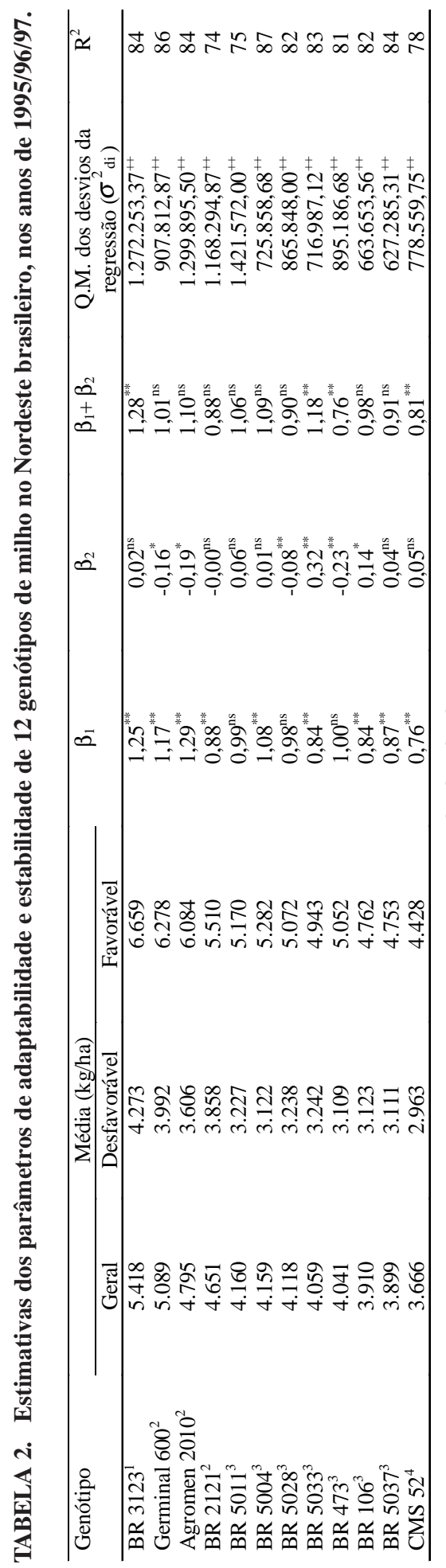

do milho nos Tabuleiros Costeiros, no Agreste e no Sertão, e no Nordeste, como um todo, respectivamente. Note-se que os Tabuleiros Costeiros, o Agreste e o Sertão produziram $0,06 \%, 4,80 \%$ e $-2,20 \%$ em relação à produtividade média dos três ecossistemas, o que mostra certa similaridade no potencial desses ecossistemas quanto à produção do milho. Esse fato reveste-se de grande importância, e pode ter ocorrido pelo fato de o regime pluvial registrado em cada local, dentro de cada região ecológica, ter sido suficiente para atender à demanda hídrica da cultura. As fontes de variação: cultivares, ambientes, e interação cultivares $\mathrm{x}$ ambientes foram significativas $(\mathrm{P} \leq 0,01)$, nos três ecossistemas e na análise global, o que evidencia diferenças entre as cultivares e os ambientes, além de mostrar que o comportamento das cultivares foi inconsistente nos diferentes ambientes, justificando-se, assim, estudo mais detalhado dessa interação. Interações significativas têm sido detectadas em trabalhos de competição de cultivares realizados na Região Nordeste (Cardoso et al., 1997; Carvalho et al., 1998a, 1998b), onde foi minimizado o seu efeito, pela seleção de cultivares com maior estabilidade fenotípica (Ramalho et al., 1993).

A produtividade média de grãos observada nos Tabuleiros Costeiros oscilou de $3.539 \mathrm{~kg} / \mathrm{ha}$ a $5.448 \mathrm{~kg} / \mathrm{ha}$, despontando os híbridos com melhor adaptação que as cultivares, merecendo destaque o híbrido triplo BR 3123, com melhor comportamento produtivo (Tabela 1). Entre as cultivares, as BR 5011 e BR 5004, de porte e ciclo normal, mostraram bom desempenho, apesar de não diferirem estatisticamente da BR 5058 e da BR 5033, de porte baixo e ciclo precoce. Essas produtividades refletem o potencial desse ecossistema para a produção do milho, o que concorda com Cardoso et al. (1997) e Carvalho et al. (1998a), que detectaram como ambientes mais favoráveis, para a produção do milho, nessa região, os tabuleiros do Piauí, áreas de renovação de cana-deaçúcar em Alagoas, e os tabuleiros de Sergipe, onde as altas produtividades alcançadas com híbridos e cultivares têm provocado aumento na área plantada com milho.

As estimativas dos parâmetros de estabilidade obtidas no ecossistema dos Tabuleiros Costeiros encontram-se na Tabela 1 . A estimativa de $\beta_{1}$, que 
avalia o desempenho das cultivares nos ambientes desfavoráveis, mostrou que o híbrido BR 2121 foi menos exigente nessa condição de ambiente $\left(\beta_{1}<1\right)$ enquanto os híbridos BR 3123 e Germinal 600 mostraram ser muito exigentes, em razão de apresentarem estimativas de $\beta_{1}$ superiores à unidade. A cultivar BR 5011, de produtividade média semelhante à média geral, e superior quando comparada com a média obtida para as cultivares $(3.980 \mathrm{~kg} / \mathrm{ha})$, mostrou ser também exigente nos ambientes desfavoráveis $\left(\beta_{1}>1\right)$,o que está em desacordo com os resultados relatados por Carvalho et al. (1992) e Cardoso et al. (1997), que obtiveram adaptabilidade ampla desse material, em vários ambientes nos estados de Sergipe e Piauí, respectivamente. As cultivares BR 5004, BR 5028 e BR 5033, de produtividades médias superiores à média das cultivares, mostraram adaptação ampla $\left(\beta_{1}=1\right)$. A estimativa de $\left(\beta_{1}+\beta_{2}\right)$, que avalia a resposta das cultivares nos ambientes favoráveis, mostrou que apenas o híbrido BR 3123 respondeu à melhoria do ambiente $\left(\beta_{1}+\beta_{2}>1\right)$. Com relação à estabilidade, nota-se que os híbridos mostraram baixa estabilidade nesse ecossistema $\left(\sigma_{\mathrm{di}}^{2} \neq 0\right)$, apesar de o híbrido BR 3123 apresentar estimativas de $\mathrm{R}^{2}$ acima de $80 \%$, o que evidencia que o grau de imprevisibilidade dessa cultivar não deve ser prejudicado (Cruz et al., 1989). As cultivares BR 5011, BR 5028 e BR 5033, com valores de $\mathrm{R}^{2}$ superiores a $80 \%$, mostram uma boa estabilidade nos ambientes considerados dentro desse ecossistema.

As estimativas dos parâmetros de estabilidade obtidas no ecossistema do Agreste estão na Tabela 1. A produtividade média foi de $4.538 \mathrm{~kg} / \mathrm{ha}$ com oscilação de $3.939 \mathrm{~kg} / \mathrm{ha}$ a $5.482 \mathrm{~kg} / \mathrm{ha}$, e demonstra o potencial desse ecossistema para a produção do milho. Os híbridos apresentaram melhor adaptação que as cultivares, sobressaindo o BR 3123, com melhor desempenho produtivo. As cultivares BR 5033, BR 106, BR 5004, BR 5011 e BR 473, apesar de apresentarem produtividades médias inferiores às da média geral, tiveram rendimentos superiores em relação à média de cultivares, o que evidencia um bom comportamento produtivo. A estimativa de $\beta_{1}$ variou de 0,69 a 1,42, e os híbridos BR 3123, Agromen 2010 e Germinal 600, por apresentarem tais estimativas superiores à unidade, revelaram-se muito exigentes, enquanto as cultivares
BR 5033 e BR 473 e a população CMS 52 foram mais estáveis nos ambientes desfavoráveis. Já as estimativas de $\left(\beta_{1}+\beta_{2}\right)$ mostraram que os híbridos BR 3123, Agromen 2010 e Germinal 600 foram mais responsivos à melhoria do ambiente $\left(\beta_{1}+\beta_{2}>1\right)$. Chama a atenção o híbrido BR 2121, que, apesar de mostrar alto rendimento, não foi responsivo à melhoria do ambiente (Tabela 1). As estimativas de $\mathrm{R}^{2}$, de todos os materiais, superiores a $80 \%$, evidenciaram bom ajustamento às retas de regressão, o que implica boa previsibilidade de resposta.

No ecossistema do Sertão (Tabela 1), onde é mais expressiva a exploração do milho no Nordeste, e onde se observa também o maior risco de cultivo em decorrência das frustrações de safras, ocasionadas pelas irregularidades climáticas, observou-se grande variação na produtividade média, despontando novamente os híbridos com melhor adaptação que as cultivares, merecendo destaque o híbrido BR 3123, com superior rendimento de grãos. No decorrer dos anos agrícolas de 1995/96/97, nota-se que as cultivares de ciclo normal (BR 106, BR 5011 e BR 5004) apresentaram rendimentos superiores em relação às precoces (BR 5028 e BR 5033) e à superprecoce (BR 5037), indicando que a quantidade e distribuição de chuvas, nesse período, não prejudicaram à produção do milho. As produtividades mais expressivas nesse ecossistema foram registradas nos sertões do Ceará, Piauí e Bahia, especialmente na região de Irecê (município de João Dourado) e em Pernambuco (Serra Talhada). A estimativa de $\beta_{1}$ evidenciou que o híbrido BR 2121 foi muito estável nos ambientes desfavoráveis $\left(\beta_{1}<1\right)$ enquanto os híbridos BR 3123, Agromen 2010 e Germinal 600 mostraram ser muito exigentes, mesmo nessa condição, por apresentarem estimativas de $\beta_{1}$ superiores às da unidade. Entre as cultivares, a BR 5033, com produtividade média superior à média das cultivares (3.891 kg/ha), mostrou ser estável em ambientes desfavoráveis, constituindo-se numa alternativa importante para a região. A BR 5037, com rendimento médio semelhante ao rendimento médio observado em cultivares, mostrou também ser estável nessa condição, o que a torna também uma alternativa importante para as regiões mais secas do Sertão, por aliar essa adaptação aos ambientes desfavoráveis à superprecocidade. Com relação à resposta nos 
ambientes favoráveis, merecem destaque as cultivares BR 106 e BR 5033, que foram as únicas cultivares a apresentar estimativas de $\beta_{1}+\beta_{1}>1$. Em termos de previsibilidade de comportamento, apenas o híbrido BR 2121, a cultivar BR 5028 e população CMS 52 foram mais instáveis, por apresentarem estimativas de $\mathrm{R}^{2}$ inferiores a $80 \%$.

As estimativas dos parâmetros de adaptabilidade e estabilidade, considerando-se os 75 ambientes distribuídos nos três ecossistemas, mostraram grande variação na produtividade média de grãos e bom discernimento entre os materiais nos ambientes desfavoráveis e favoráveis (Tabela 2). Os híbridos mostraram melhor adaptação que as cultivares, superando-as em $23,2 \%$, merecendo destaque o híbrido BR 3123, que teve o melhor rendimento médio. As cultivares mostraram rendimento médio inferior ao da média geral, apesar de as BR 106, BR 5011, BR 5004, BR 5033 e BR 5028, de rendimentos médios superiores aos da média observada em cultivares $(4.001 \mathrm{~kg} / \mathrm{ha})$, expressarem alto potencial para a produtividade, o que justifica seus usos em sistemas de produção tecnificados e nos sistemas com pouca ou nenhuma tecnificação, comuns nas pequenas e médias propriedades rurais da Região Nordeste, onde, certamente, provocarão substancial melhoria na renda dessas propriedades.

O híbrido BR 3123 mostrou a maior estimativa de $\beta_{0}$ dentro de cada ecossistema e no Nordeste como um todo, caracterizando-se como o material de maior potencial com vistas à produtividade, apesar de ser muito exigente, haja vista que sua estimativa de $\beta_{1}$ foi sempre superior à unidade em todos os ecossistemas e na análise geral. O referido híbrido mostrou ainda como vantagens, resposta positiva à melhoria ambiental $\left(\beta_{1}+\beta_{2}>1\right)$ nos ecossistemas do Agreste, do Sertão e do Nordeste brasileiro, e boa estabilidade de produção, em todas as situações, $\left(\mathrm{R}^{2}>80 \%\right)$, qualificando-se como excelente alternativa para uso na região.

Os híbridos Agromen 2010 e Germinal 600, de altos rendimentos médios, mostraram também ser muito exigentes no Nordeste como um todo, com estimativas de $\beta_{1}>1$, além de mostrar alta previsibilidade de resposta, com estimativas de $\mathrm{R}^{2}>80 \%$ (Tabela 2 ). O híbrido BR 2121, de alta produtividade, mostrou ser estável nos ambientes desfavoráveis $\left(\beta_{1}<1\right)$, e o mais instável na região, por apresentar a menor estimativa de $\mathrm{R}^{2}$ (74\%) (Tabela 2). Este material, dada sua alta qualidade protéica, a qual, associada ao seu potencial produtivo e à sua adaptação nos ambientes desfavoráveis, desperta grande interesse para a região, onde terá grande utilidade na suplementação da dieta alimentar e na formulação de ração para animais monogástricos.

A cultivar BR 5011-Sertanejo, de ciclo semitardio, mostrou ser muito exigente nos ambientes desfavoráveis $\left(\beta_{1}>1\right)$ (Tabela 2$)$, pois repetiu o comportamento apresentado no ecossistema dos Tabuleiros, o que está em desacordo com os resultados relatados por Carvalho et al. (1992) e Cardoso et al. (1997), que detectaram ampla adaptabilidade dessa cultivar, à semelhança do ocorrido nos ecossistemas do Agreste e Sertão. Esta cultivar mostrou também alta previsibilidade de resposta nos ambientes considerados $\left(\mathrm{R}^{2}>80 \%\right)$ (Tabela 2$)$, à semelhança do constatado dentro de cada ecossistema, e à semelhança, também, dos resultados relatados pelos autores citados, o que justifica sua recomendação para a região. A cultivar BR 106, também de ciclo semitardio, de ampla divulgação no Nordeste, apresentou produtividade média superior à média relativa a cultivares, e baixa estabilidade nos ambientes considerados (Tabela 2), à semelhança do que ocorreu no ecossistema dos Tabuleiros. Este resultado discorda do obtido por Carvalho et al. (1992) e Cardoso et al. (1997), que encontraram, nessa cultivar, alta estabilidade de produção, o que justifica também sua exploração na região.

A cultivar BR 5033, de ciclo precoce, também bastante difundida no Nordeste, se aproximou do genótipo ideal proposto pelo modelo de Cruz et al. (1989), por apresentar média alta, em comparação com a média obtida no que diz respeito a cultivares $(4.001 \mathrm{~kg} / \mathrm{ha})$, adaptação nos ambientes desfavoráveis $\left(\beta_{1}<1\right)$, resposta à melhoria do ambiente $\left(\beta_{1}+\beta_{2}>1\right)$, e alta previsibilidade de resposta $\left(\mathrm{R}^{2}=83 \%\right)$ (Tabela 2). Essa cultivar mostrou alta previsibilidade de resposta dentro de todos os ecossistemas e adaptação aos ambientes desfavoráveis nos ecossistemas do Agreste e do Sertão, justificando, assim, sua recomendação para o Nordeste, especialmente, para o ecossistema do Sertão, dada a sua precocidade. Resultados relatados por Carvalho et al. $(1992,1998 b)$ e 
Cardoso et al. (1997) registraram também alta estabilidade dessa cultivar. A cultivar BR 5028-São Francisco, de ciclo precoce, mostrou bom rendimento médio e alta previsibilidade de resposta (Tabela 2), à semelhança do ocorrido nos trabalhos relatados por Carvalho et al. (1992, 1998b) e Cardoso et al. (1997), o que justifica sua recomendação na região, onde já é amplamente explorada.

A presença de correlação significativa e positiva $\left(\mathrm{r}=0,81^{* *}\right)$ entre os rendimentos médios das cultivares e as estimativas de $\beta_{1}$ mostram que as cultivares com melhores rendimentos foram mais exigentes nas condições desfavoráveis (Tabela 2), no tocante aos híbridos BR 3123, Agromen 2010 e Germinal 600. Observou-se também ausência de correlação $(\mathrm{r}=0,23 \mathrm{~ns})$ entre as produtividades médias e os parâmetros de estabilidade $\left(\mathrm{R}^{2}\right)$, evidenciando-se, assim, que essas características devam ter controle genético independente, a exemplo do registrado por Torres (1988).

As cultivares avaliadas, de diferentes bases genéticas, mostraram boa estabilidade, à exceção do híbrido duplo BR 2121, da cultivar BR 106, e da população CMS 52. Constata-se que tanto o híbrido triplo BR 3123, de menor base genética, e os híbridos duplos, Agromen 2010 e Germinal 600 e cultivares, de maior base genética mostraram alta estabilidade nos ambientes considerados dessa ampla região, evidenciando-se que a estabilidade de produção desses materiais foi ocasionada pela heterozigose $\mathrm{e}$ heterogeneidade, e, provavelmente, por uma interação desses fatores.

\section{CONCLUSÕES}

1. Os híbridos mostram melhor adaptação que as cultivares, e se qualificam como excelentes alternativas para a região.

2. As cultivares, de diferentes portes e ciclos, constituem alternativas importantes para sistemas de produção tecnificados, e para os sistemas praticados por pequenos e médios produtores.

3. Para o ecossistema do Sertão, a recomendação de cultivares precoces (BR 5028 e BR 5033) e superprecoce (BR 5037) garantem menor risco do cultivo.
4. Para os Tabuleiros Costeiros, é mais vantajosa a recomendação de cultivares de ciclo normal, por serem mais produtivas.

5. Para o Agreste, a recomendação de cultivares de ciclos precoce e normal possibilita a obtenção de melhores rendimentos.

6. Para a Região Nordeste, a cultivar BR 5033 se aproxima do genótipo ideal proposto pelo modelo utilizado.

\section{REFERÊNCIAS}

ALLARD, R.W.; BRADSHAW, A.D. Implications of genotype environmental interactions in applied plant breeding. Crop Science, Madison, v.4, n.5, p.503528, 1964.

ANUÁRIO ESTATÍSTICO DO BRASIL. Rio de Janeiro : IBGE, v.53, 1995.

ARIAS, E.R.A. Adaptabilidade e estabilidade de cultivares de milho avaliados no Estado do Mato Grosso do Sul e avanço genético obtido no período de 1986/87 e 1993/94. Lavras : ESAL, 1996. 118p. Tese de Doutorado.

CARDOSO, M.J.; CARVALHO, H.W.L. de; PACHECO, C.A.P.; SANTOS, M.X. dos; LEAL, M. de L. da S. Adaptabilidade e estabilidade de cultivares de milho no Estado do Piauí, no biênio 1993/94. Revista Científica Rural, Bagé, v.2, n.1, p.35-44, 1997.

CARVALHO, H.W.L. de; MAGNAVACA, R.; LEAL, M. de L. da S. Estabilidade de produção de cultivares de milho no Estado de Sergipe. Pesquisa Agropecuária Brasileira, Brasília, v.27, n.7, p.1073-1082, jul. 1992.

CARVALHO, H.W.L. de; PACHECO, C.A.P.; SANTOS, M.X. dos; LEAL, M. de L. da S. Estabilidade de cultivares de milho no Estado de Sergipe. Revista Científica Rural, Bagé, v.3, n.1, p.15-22, 1998a.

CARVALHO, H.W.L. de; SANTOS, M.X. dos; LEAL, M. de L. da S.; PACHECO, C.A.P.; CARVALHO, B.C.L. de; LIRA, M.A. Adaptabilidade e estabilidade de cultivares de milho no Nordeste brasileiro no ano de 1995. Revista Científica Rural, Bagé, v.3, n.1, p.8-14, 1998b.

COSTA, S.V. Interação de cultivares de milho (Zea mays L.) $\mathrm{x}$ anos $\mathrm{x}$ localidades nos Estados do Piauí e do Maranhão, Brasil. Piracicaba : ESALQ, 1976. 82p. Dissertação de Mestrado. 
CRUZ, C.D.; TORRES, R.A. de; VENCOVSKY, R. Alternative approach to the stability analysis proposed by Silva and Barreto. Revista Brasileira de Genética, Ribeirão Preto, v.12, n.13, p.567-582, 1989.

LEMOS, M.A. Variabilidade fenotípica em híbridos simples, variedades e compostos de milho. Piracicaba : ESALQ, 1976. 62p. Dissertação de Mestrado.

NASPOLINI FILHO, W. Variabilidade fenotípica e estabilidade em híbridos simples, híbridos duplos, variedades e compostos de milho. Piracicaba : ESALQ, 1976. 68p. Dissertação de Mestrado.

PATERNIANI, R. Seleção recorrente para capacidade geral de combinação em milhos da América Central. Ciência e Cultura, São Paulo, v.17, p.555-559, 1965.

RAMALHO, M.A.P.; SANTOS, J.B. dos; ZIMMERMANN, M. J. de O. Interação dos genótipos x ambientes. In: RAMALHO, M.A.P.; SANTOS, J.B. dos; ZIMMERMANN, M.J. de O. (Ed.). Genética quantitativa em plantas autógamas: aplicação no melhoramento do feijoeiro. Goiânia : Ed. da UFG, 1993. p.131-169. (Publicação, 120).
RUSCHEL, R. Interação genótipo $\mathbf{x}$ localidade na região Centro-Sul em millho (Zea mays L.). Piracicaba : ESALQ, 1968. 60p. Dissertação de Mestrado.

RUSCHEL, R.; PENTEADO, F. Análise dos componentes da variância de duas classes de cultivares de milho e estimativa do progresso genético médio em ensaios de produção. Pesquisa Agropecuária Brasileira, Brasília, v.5, n.3, p.381-388, mar. 1970.

SCAPIM, C.A.; CARVALHO, C.G.P. de; CRUZ, C.D. Uma proposta de classificação dos coeficientes de variação para a cultura do milho. Pesquisa Agropecuária Brasileira, Brasília, v.30, n.5, p.683686, maio 1995.

SILVA, F.B.R. de; RICHE, G.R.; TORNGAU, J.P.; SOUZA NETO, N.C. de; BRITO, L.T. de L.; CORREIA, R.C.; CAVALCANTI, A.C.; SILVA, F.H.B.B. da; SILVA, A.D. da; ARAÚJO FILHO, J.C. de; LEITE, A.P. Zoneamento ecológico do Nordeste: diagnóstico do quadro natural e agrosocioeconômico. Petrolina : Embrapa-CPATSA/Embrapa-CNPS, 1993. v.1.

TORRES, R.A. de A. Estudo do controle genético da estabilidade fenótipica de cultivares de milho (Zea mays L.). Piracicaba : ESALQ, 1988. 133p. Dissertação de Mestrado. 